See Article page 12.

\section{Commentary: Daytime or nighttime acute type $A$ aortic dissection repair? Does it really matter?}

\author{
Abdulrhman S. Elnaggar, MD, \\ Faisal G. Bakaeen, MD, Eric E. Roselli, MD, \\ Lars G. Svensson, MD, $\mathrm{PhD}$, and \\ Patrick R. Vargo, MD
}

Acute type A aortic dissection (ATAAD) is a lifethreatening condition and a true surgical emergency with a mortality rate of $1 \%$ to $2 \%$ per hour and overall mortality of $60 \%$ at 48 hours if not treated surgically. ${ }^{1-3}$ Emergency open surgical repair remains the gold standard and is shown to reduce in-hospital mortality to $15 \%$ to $25 \%$. $^{4,5}$ Based on different clinical presentations, patients with ATAAD could be grouped into different categories that determine the optimal management strategy. Immediate surgical repair is recommended in the presence of coronary or cerebral malperfusion or acute aortic insufficiency. On the other hand, in patients with visceral or limb malperfusion at the forefront of their presentation, it is reasonable to address visceral and/or limb ischemia first, particularly in the face of significant metabolic derangement or concerns about bowel viability. ${ }^{6}$ In reasonably stable patients, a transfer to a dedicated aortic center should be considered. ${ }^{7}$ A significant pericardial effusion with impending tamponade may be drained before the transfer. Several studies have demonstrated improved outcomes following ATAAD repair in high volume aortic centers with teams experienced in open and endovascular surgery. ${ }^{8}$ However, there are

\footnotetext{
From the Department of Thoracic and Cardiovascular Surgery, Aortic Center, Cleveland Clinic, Cleveland, Ohio.

Disclosures: The authors reported no conflicts of interest.

The Journal policy requires editors and reviewers to disclose conflicts of interest and to decline handling or reviewing manuscripts for which they may have a conflict of interest. The editors and reviewers of this article have no conflicts of interest.

Received for publication May 18, 2021; revisions received May 18, 2021; accepted for publication May 21, 2021; available ahead of print June 2, 2021.

Address for reprints: Patrick R. Vargo, MD, Department of Thoracic and Cardiovascular Surgery, Aortic Center, Cleveland Clinic, 9500 Euclid Ave, J4-1, Cleveland, OH 44195 (E-mail: vargop3@ccf.org).

JTCVS Open 2021;7:21-2

2666-2736

Copyright (c) 2021 The Author(s). Published by Elsevier Inc. on behalf of The American Association for Thoracic Surgery. This is an open access article under the CC BY-NC-ND license (http://creativecommons.org/licenses/by-nc-nd/4.0/).

https://doi.org/10.1016/j.xjon.2021.05.008
}

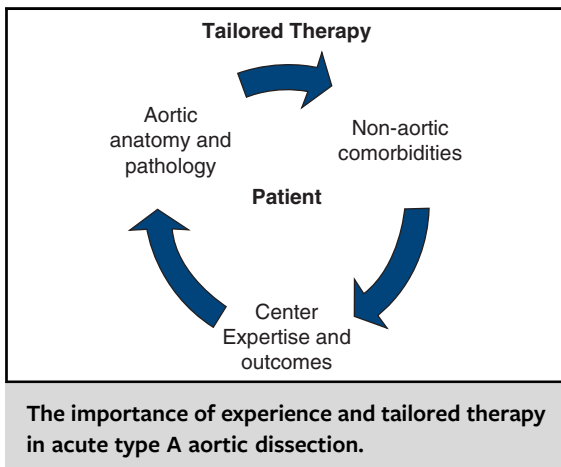

CENTRAL MESSAGE

Surgical repair of acute type A aortic dissection has evolved over time and a dedicated team with open and endovascular expertise can optimize outcomes regardless of the time of day.

conflicting data regarding the impact of daytime versus nighttime surgery on the outcomes of surgical repair. ${ }^{9,10}$

Harky and colleagues ${ }^{11}$ took an interesting approach and investigated the timing of surgical repair of ATAAD in correlation with the establishment of dedicated aortic teams. The authors demonstrated that at their hospital, there was no difference in 30-day mortality following ATAAD repair whether the surgery was performed during the daytime or nighttime. They also demonstrated that the establishment of a dedicated aortic team played a major role in reducing postoperative mortality following ATAAD repairs despite the performance of more extensive repairs, including frozen elephant trunks compared with the preaortic team era. One unexpected finding is the increase in duration between presentation and surgery in the specialized aortic team era.

This study comes with the inherit limitation of being a single-center retrospective study with lack of granularity regarding the clinical presentation, including hemodynamic stability and the nature of the malperfusion syndromes. Therefore, it is not possible to determine the percentage of patients with hyperacute features and appropriately adjust for them. In addition, we do not have the true denominator of patients who presented with ATAAD because those who were declined surgery or died before surgery were not captured. Nevertheless, this report is an important addition to the current literature on the surgical management of ATAAD and its findings are consistent with the 2021 American Association for Thoracic Surgery Expert 
Consensus on surgical treatment of acute type A aortic dissection. ${ }^{12}$

Several technical advances have been made during the past decade in the care of patients with ATAAD, such as the frozen elephant trunk technique and its many variations, as well as a number of promising endovascular strategies that could be offered to a group of patients otherwise deemed inoperable. A dedicated team facile with those innovations can provide timely and optimal care and optimize patient outcomes.

\section{References}

1. Hagan PG, Nienaber CA, Isselbacher EM, Bruckman D, Karavite DJ, Russman PL, et al. The International Registry of Acute Aortic Dissection (IRAD): new insights into an old disease. J Am Med Assoc. 2000;283:89-903.

2. Hirst AE, Johns VJ, Kime SW. Dissecting aneurysm of the aorta: a review of 505 cases. Medicine (Baltimore). 1958:37:217-79.

3. Svensson LG, Crawford ES. Aortic dissection and aortic aneurysm surgery: clinical observations, experimental investigations, and statistical analyses part II. Curr Probl Surg. 1992;29:913-1057.

4. Svensson LG, Crawford ES, Hess KR, Coselli JS, Safi HJ. Dissection of the aorta and dissecting aortic aneurysms. Improving early and long-term surgical results. Circulation. 1990;82(5 Suppl):IV24-38.
5. Sultan I, Bianco V, Patel HJ, Arnaoutakis GJ, Di Eusanio M, Chen EP, et al. Surgery for type A aortic dissection in patients with cerebral malperfusion: results from the International Registry of Acute Aortic Dissection. J Thorac Cardiovasc Surg. 2021;161:1713-20.

6. Yang B, Rosati CM, Norton EL, Kim KM, Khaja MS, Dasika N, et al. Endovascular fenestration/stenting first followed by delayed open aortic repair for acute type A aortic dissection with malperfusion syndrome. Circulation. 2018;138: 2091-103.

7. Goldstone AB, Chiu P, Baiocchi M, Lingala B, Lee J, Rigdon J, et al. Interfacility transfer of medicare beneficiaries with acute type A aortic dissection and regionalization of care in the United States. Circulation. 2019;140:1239-50.

8. Mariscalco G, Maselli D, Zanobini M, Ahmed A, Bruno VD, Benedetto U, et al. Aortic centres should represent the standard of care for acute aortic syndrome. Eur J Prev Cardiol. 2018;25(1 Suppl):3-14.

9. Arnaoutakis G, Bianco V, Estrera AL, Brinster DR, Ehrlich MP, Peterson MD, et al. Time of day does not influence outcomes in acute type A aortic dissection: results from the IRAD. J Card Surg. 2020;35:3467-73.

10. Qiu J, Zhang L, Luo X, Gao W, Liu S, Jiang W, et al. Higher mortality in patients undergoing nighttime surgical procedures for acute type A aortic dissection. Ann Thorac Surg. 2018;106:1164-70.

11. Harky A, Mason S, Othman A, Shaw M, Nawaytou O, Harrington D, et al. Outcomes of acute type A aortic dissection repair: daytime versus nighttime. $J$ Thorac Cardiovasc Surg Open. 2021;7:12-20.

12. Malaisrie SC, Szeto WY, Halas M, Girardi LN, Coseli JS, Sundt TM III, et al. 2021 American Association for Thoracic Surgery (AATS) expert consensus document: surgical treatment of acute type A aortic dissection. J Thorac Cardiovasc Surg. 2021;162:735-58.e2. 